\title{
IMPACTOS E DESAFIOS DO ENSINO ON-LINE DECORRENTES DA PANDEMIA COVID-19
}

\author{
IMPACTOS Y RETOS DE LA EDUCACIÓN EN LÍNEA DERIVADOS DE LA \\ PANDEMIA COVID-19
}

\author{
IMPACTS AND CHALLENGES OF ONLINE EDUCATION ARISING FROM COVID- \\ 19 PANDEMIC
}

\author{
Elizabeth Matos ROCHA ${ }^{1}$ \\ Juliana Maria da Silva LIMA ${ }^{2}$
}

RESUMO: Este artigo objetiva refletir sobre os impactos e desafios impostos ao ensino online, em território brasileiro, em 2020, um ano atípico, dada à incidência e readequação da agenda educacional imposta pela pandemia da COVID-19. Para isso, abordou-se o marco regulatório expedido pelo governo federal brasileiro e pelo MEC, apresentando as normativas específicas na Universidade Federal da Grande Dourados -UFGD. Mostrou-se que as modalidades de educação presencial e a distância sofreram impactos relacionados à alteração da agenda e do formato pedagógico, visto que cursos de graduação $\mathrm{EaD}$, devido ao Decreto $\mathrm{n}^{\mathrm{o}}$ 9057/2017 (BRASIL, 2017), geram em algum momento, fluxo social. Admite-se que tem ocorrido mudanças de comportamento da sociedade na vivência do ensino remoto subsidiado por um conjunto normativo e de disponibilização tecnológica, sobretudo, as que viabilizam as aulas no formato de webconferências.

PALAVRAS-CHAVE: COVID-19. Ensino presencial. Ensino a distância.

RESUMEN: Este artículo tiene como objetivo reflexionar sobre los impactos y desafios impuestos a la educación en línea, en el territorio brasileño, en 2020, un año atípico, dada la incidencia y reajuste de la agenda educativa impuesta por la pandemia COVID-19. Para ello, se abordó el marco regulatorio emitido por el gobierno federal y el MEC, presentando la normativa específica en la UFGD. Se demostró que las modalidades de educación presencial y a distancia han sufrido impactos relacionados con la alteración de la agenda y el formato pedagógico, ya que los cursos de educación a distancia de pregrado, debido al Decreto $n^{\circ}$ 9057/2017, generan también en algún momento flujo social. Se admite que se ha producido un cambio en el comportamiento de la sociedad en la experiencia de la educación a distancia subvencionada por un conjunto de estándares y disponibilidad tecnológica, especialmente aquellas que hacen factibles las clases a través de conferencias web.

PALABRAS CLAVE: COVID-19. Enseñanza presencial. Enseñanza a distancia.

1 Universidade Federal da Grande Dourados (UFGD), Dourados - MS - Brasil. Professora Associada I e Diretora da Faculdade de Educação a Distância. Doutorado em Educação (UFC). ORCID: https://orcid.org/00000002-5977-9499. E-mail: elizabethrocha@ufgd.edu.br

${ }^{2}$ Universidade Federal da Grande Dourados (UFGD), Dourados - MS - Brasil. Professora do Magistério Superior da Faculdade de Educação a Distância. Doutorado em Educação (UFGD). ORCID: https://orcid.org/0000-0003-1785-2819.E-mail: julianamaria@ufgd.edu.br 
ABSTRACT: This paper aims to reflect on the impacts and challenges imposed on online education, in Brazilian territory, in 2020, an atypical year, given the incidence and readjustment of the educational agenda imposed by the COVID-19 pandemic. Thus, the regulatory framework issued by the federal government and MEC was addressed, presenting the specific regulations at UFGD. It was shown that the modalities of face-to-face and distance education suffered impacts related to the alteration of the agenda and the pedagogical format, since undergraduate distance education courses, due to Decree $n^{o}$ 9057/2017, generate social flow at some point, too. It is admitted that there has been a change in the behavior of society in the experience of remote education subsidized by a set of standards and technological availability, especially those that make classes via web conferences feasible.

KEYWORDS: COVID-19. Face-to-face teaching. Distance education.

\section{Introdução}

De acordo com o Art. 43 da Lei de Diretrizes e Bases da Educação - LDB 9.394/1996 (BRASIL, 1996), dentre outros objetivos, a Educação Superior tem por finalidade estimular a criação cultural e o desenvolvimento do espírito científico e do pensamento reflexivo. Tomando-se como base que o pensamento reflexivo na educação requer analisar o percurso da trajetória didático-pedagógica que se propõe dar as condições necessárias para que o educando tenha pleno desenvolvimento da sua cognição, emoção e personalidade, constata-se que refletir sobre a educação, não somente tem que ser ou precisa pautar-se em uma garantia legal, mas sim, um princípio desejável.

Com base nisso, este artigo objetiva refletir sobre os impactos e desafios impostos ao ensino on-line, em território brasileiro, em 2020, um ano atípico, dada à incidência e readequação da agenda educacional imposta pela pandemia da COVID-19. O rápido contágio entre humanos, a alta taxa de mortalidade e a falta de vacina, impuseram confinamento à humanidade, no formato lockdown, desde março de 2020.

Quando usamos o termo ensino on-line somos levados de imediato à Educação a Distância (EaD), pois segundo o Decreto 9.057/2017 (BRASIL, 2017), que regulamenta o Art. 80 da LDB 9.394/1996 (BRASIL, 1996), vincula a EaD às tecnologias digitais, de forma compatível aos princípios defendidos à educação, na Constituição Federal brasileiria de 1988 (BRASIL, 1988). O Decreto 9.057/2017 (BRASIL, 2017), que revogou o Decreto 5.622/2005 (BRASIL, 2005), em seu Art. $1^{\text {o }}$, considera Educação a Distância como “a modalidade educacional na qual a mediação didático-pedagógica nos processos de ensino e aprendizagem ocorra com a utilização de meios e tecnologias de informação e comunicação". 
Isso porque, usar tecnologias que garantam o fluxo da informação e da comunicação, como o sistema postal, comunicações por satélites, radiotransmissão, dentre outras tecnologias a esse fim, são inerentes à $\mathrm{EaD}$, dada a dependência que essa modalidade educacional tem de tecnologias que viabilizem o fluxo da informação e da comunicação em seu modus operandi, já que professores e estudantes, no desenvolvimento dos seus papéis vinculados ao ensino e à aprendizagem, estão, via de regra, em lugares e tempos diversos (WENCZENOVICZ, 2020).

No entanto, com as especificidades impostas pela COVID-19 aos diversos setores da sociedade, no território brasileiro e, também, mundial, o ensino on-line ao qual nos reportamos neste texto, abarca, também, o universo do ensino presencial, não se limitando à EaD.

Para subsidiar as reflexões deste artigo, nos pautamos no conjunto normativo expedido, desde março/2020, pelo Governo Federal, Ministério da Economia/Secretaria Especial de Desburocratização, Gestão e Governo Digital/Secretaria de Gestão e Desempenho de Pessoal, Ministério da Educação e Cultura, que reverberaram no ensino presencial e de Educação a Distância da Universidade Federal da Grande Dourados (UFGD).

Destacamos, portanto, os impactos e desafios que sobrevieram aos professores e estudantes na oferta de ensino remoto, de forma on-line. Apontamos, ainda, o papel da pandemia nesse cenário, considerando conceitos ensinados, mas, também, outros, aprendidos, destacando, por fim, elementos que prospectam mudanças na concepção educacional, doravante.

\section{Afinal, quais impactos e desafios se apresentam no ensino remoto?}

Com misto de espanto e desconforto, a sociedade brasileira, com ênfase nas Instituições Públicas de Ensino Superior (IES), tiveram acesso à Lei $n^{\circ} 13.979$, de 06 de fevereiro de 2020 (BRASIL, 2020,) que dispõe sobre "as medidas para enfrentamento da emergência de saúde pública de importância internacional decorrente do coronavírus responsável pelo surto de 2019”. No âmbito do Sistema de Pessoal Civil da Administração Pública Federal - SIPEC, estabeleceu, por meio da Instrução Normativa ${ }^{\circ}$ 19, de 12 de março de 2020 (BRASIL, 2020), expedida pelo Ministério da Economia, as orientações necessárias “quanto às medidas de proteção para enfrentamento da emergência de saúde pública de importância internacional decorrente do coronavírus (COVID-19).” 
O conjunto normativo para garantir o isolamento social, no âmbito educacional, incluiu a Portaria MEC n 343, de 17 de março de 2020 (BRASIL, 2020,), que “dispõe sobre a substituição das aulas presenciais por aulas em meios digitais enquanto durar a situação de pandemia do Novo Coronavírus - COVID-19”, e, ainda, a Medida Provisória n 934, de 01 de abril de 2020 (BRASIL, 2020,), que "estabelece normas excepcionais sobre o ano letivo da educação básica e do ensino superior decorrentes das medidas para enfrentamento da situação de emergência de saúde pública de que trata a Lei no 13.979, de 6 de fevereiro de 2020”.

Esse subsídio legal impactou, de imediato, nas IES, readequação administrativa e pedagógica, dado o início do semestre letivo de 2020.1 que vinha sendo executado rotineiramente, espelhados nos planos de ensino das disciplinas dos muitos realizados no ensino presencial ou no ensino a distância.

$\mathrm{Na}$ UFGD, o embasamento legal que visou adequação e alinhamento com as normativas do governo federal para evitar o contato social contemplou, dentre outros documentos, a Portaria RTR no 194, de 13 de março de 2020 (UFGD, 2020), para suspensão de viagens, atividades, eventos, reuniões, dentre outras tratativas; Instrução Normativa $n^{\circ} 04$, de 17 de março de 2020, que instituiu o teletrabalho nas unidades acadêmicas e administrativas; Portaria $\mathrm{n}^{\circ}$ 205, de 18 de março de 2020, que suspendeu o calendário acadêmico por 30 dias, sendo revogada pela Portaria $n^{\circ} 249$, de 13 de abril de 2020, que prorrogou "Sine Die" a suspensão do calendário acadêmico.

Esse leque normativo, de forma impositiva pela situação pandêmica, mexeu com a lógica do ensino presencial marcada pela movimentação de professores, estudantes, técnicos, profissionais terceirizados, nas paradas de ônibus, nos estacionamentos, na lanchonete para o cafezinho, no restaurante universitário, na biblioteca, nos laboratórios, nas muitas salas de aula.

Houve, igualmente, impacto nos cursos de graduação ofertados pela EaD/UFGD, visto que seu modelo pedagógico gera, também, fluxo social no encontro presencial mensal previsto no calendário acadêmico, mesmo com um ensino que ocorre, durante o mês, com a utilização de e-books, sites, livros eletrônicos, ambiente virtual de aprendizagem MOODLE (AVA), videoaulas, além de interação assíncrona com o estudante nos fóruns virtuais e nos grupos de WhatsApp. Logo, não é pelo fato de desenvolver $\mathrm{EaD}$, em ambiente web, que estudantes e professores da rede federal de ensino não se veem, presencialmente, para dar continuidade ao momento pedagógico on-line, e, ao menos por algumas horas, vivenciar a interlocução verbal frente a frente, professores e estudantes, de modo análogo ao ensino presencial.

RIAEE - Revista Ibero-Americana de Estudos em Educação, Araraquara, v. 16, n. 2, p. 377-390, abr./jun. 2021. e-ISSN: 1982-5587 
Feita a contextualização é preciso considerar que a interrupção da agenda pedagógica relativa ao fluxo social de ambas modalidades educacionais só ocorreu a partir do suporte legal emitido pelo governo federal para enfrentamento de emergência da saúde pública de importância internacional decorrente do coronavírus (COVID-19), quando da publicação da Instrução Normativa $n^{0}$ 19/2020 aos órgãos do SIPEC, reavaliando de forma criteriosa, viagens de servidores, realização presencial de reuniões e eventos presenciais, aceite de atestados digitais, delimitação e manutenção dos serviços essenciais por parte dos dirigentes.

De forma mais específica à educação, a Portaria MEC no 343/2020 (BRASIL, 2020), revogada pela Portaria MEC no 544/2020 (BRASIL, 2020), dispõe sobre a substituição das aulas presenciais por aulas em meio digitais. Quanto à Medida Provisória $n^{\circ}$ 934/2020 (BRASIL, 2020), convertida na Lei $\mathrm{n}^{\circ} 10.040 / 2020$ (BRASIL, 2020) teve o papel de estabelecer normas excepcionais para o ano letivo na Educação Básica e Superior, dispensando-as, "em caráter excepcional, da obrigatoriedade de observância ao mínimo de dias de efetivo trabalho acadêmico, nos termos do caput e no $\$ 3^{\circ}$ do art. 47 da Lei $n^{\circ}$ 9394/1996".

Tal marco regulatório, saliente-se, excepcional, foi suficiente para trazer à existência, nas IES, documentos normativos que ajudassem, de forma rápida, nos encaminhamentos para superação de momento tão nevrálgico a todos. Na UFGD, para ilustrar, houve publicações da Portaria RTR n ${ }^{\circ}$ 194/2020, que suspendeu as atividades presenciais, na UFGD; Instrução Normativa PROGESP $n^{\circ}$ 04/2020 que orientou o teletrabalho na UFGD; Portaria RTR $n^{0}$ 205/2020, que suspendeu o calendário acadêmico por 30 dias, sendo prorrogado "Sine Die", pela Portaria RTR nº 249/2020.

A paralisação do calendário acadêmico na UFGD trouxe impacto para a Faculdade de Educação a Distância na medida em que se identificou diversos espaços escolares, sobretudo na Educação Básica e, fez migrarem seus professores e estudantes para o ensino on-line. Pareceu contraditório que cursos já veiculados em ambiente web tivessem suas aulas suspensas, de modo que identificar o funcionamento laboral, de modo remoto, de espaços escolares e não escolares, foi decisivo para que o retorno das aulas na EaD/UFGD voltasse às aulas no dia 02/05/2020, com a publicação da Portaria n 253/2020.

Enquanto a EaD/UFGD teve a perda de um mês letivo, o ensino presencial da UFGD suspendeu o semestre letivo 2020.1, voltando às aulas no semestre 2020.2, em 03/08/2020, por meio da Portaria RTR $\mathrm{n}^{\mathrm{o}} 367 / 2020$, de forma remota, em caráter emergencial e excepcional. Para isso, a UFGD disponibilizou formações continuadas para todos os docentes para que se sentissem seguros quanto à mediação, edição, diagramação de aulas em ambientes 
virtuais MOODLE e Google Classroom, gravação, edição e publicação de vídeos na plataforma YouTube.

No entanto, a readequação do formato de aulas presenciais para ambientes virtuais não foi uma realidade personalizada da UFGD. Escolas, universidades, cursos de formação no Brasil e no mundo migraram seus professores, estudantes e equipe de gestão para plataformas de webconferências, como a conferência $W e b$ da Rede Nacional de Pesquisa - RNP, o Google Meet, a Microsoft Teams e, até mesmo o WhatsApp disponibilizou, desde junho de 2020, salas de conferência pela ferramenta Messenger. Sem dúvida, a situação emergencial provocada pelo coronavírus (COVID-19) quebrou, mesmo que de forma abrupta, resistências para uso de tecnologias digitais na educação, por parte da sociedade.

\section{Aspectos da técnica e da tecnologia que a pandemia nos revela}

Ao observar a trajetória da raça humana, desde os primórdios de nossas origens, identificamos a capacidade cognitiva do desenvolvimento de técnicas, enquanto "habilidade de/para fazer algo, uma espécie de conhecimento específico para que uma determinada função seja desempenhada", como aponta Kussler (2015, p. 188-189). No entanto, a técnica carece ser efetivada ao cenário ao qual se presta e como isso dando significado à incorporação da tecnologia, que, nas palavras de Kussler (2015, p. 189), como sendo:

[...] um processo mais elaborado, responsável pela criação e pelo desenvolvimento de inúmeros produtos, e no estudo científico que envolve tal processo criatório. Novamente, etimologicamente falando, tecnologia é o próprio dizer da técnica, ou seja, o modo como ela é organizada, elencada, sistematizada e pensada (KUSSLER, 2015, p. 189).

Desse modo, tanto a técnica, como a tecnologia a ela vinculada, surgem e se transformam em contexto de necessidade humana, "expressa como uma astúcia criativa", como ressalta Kussler (2015, p. 189), sempre em resposta aos fatores diversos da dimensão humana, como por exemplo, a economia, cultura, saúde, política, arte, educação, dentre outras. No momento atual, o contexto de necessidade da raça humana, frente à pandemia, requer superação, evitando o fluxo social, mas com a garantia de continuidade das atividades básicas da sociedade. Trata-se de campo de aplicação que nos revela, no mínimo, três aspectos interessantes em que é possível constatar as estratégias tecnológicas em transformação para superação das limitações impostas pelo isolamento social.

$\mathrm{O}$ primeiro aspecto se vincula à mudança de comportamento da sociedade para disponibilização e uso de plataformas de webconferências que viabilizam reuniões virtuais. 
Em apenas cinco meses, de abril a agosto de 2020, o Brasil e diversos países do mundo, em consequência ao isolamento social, migraram diversas atividades presenciais para plataformas de trabalho remoto. Participaram desse movimento, o setor público e o privado, como empresas, escolas, universidades. Isso só foi possível porque empresas que oferecem serviço de plataformas de webconferência, viram-se estimuladas a disponibilizar à população nesse período, inclusive, gratuitamente, uma versão mais básica para comunicação de várias pessoas, em tempo real, simultaneamente.

Se por um lado, a organização e sistematização de plataformas como o Zoom, Hangout Google Meet, Messenger Rooms, Skype, YouTube, Facebook, sofreram transformações em suas técnicas e tecnologias, de forma célere a fim de possibilitar ao usuário mais conforto, comodidade, de modo a reverter maior visibilidade na disputa de mercado, por outro lado, pessoas de várias gerações se dispuseram a aprender como essas tecnologias funcionam, bem como, aos poucos, têm absorvido a comunicação com o outro por meio da tela do computador ou do celular.

Esse cenário foi registrado quantitativamente, pela revista Forbes ${ }^{3}$ em 27 de abril de 2020, por meio de uma pesquisa desenvolvida pela SEMrush, companhia norte americana especializada em marketing digital, que apresenta, como caso de sucesso, o home office e a transferência de aulas presenciais para plataformas de webconferência. De acordo com a pesquisa, no dia 01 de abril de 2020, mais de 25 milhões de reuniões foram realizadas de maneira on-line em todo o mundo pela plataforma Zoom, contribuindo para que ações da empresa saísse de US\$ 68, em janeiro, para US\$ 150,25, em 22 de abril de 2020. É importante que se ressalte que a plataforma Zoom já estava em pleno uso antes da pandemia, só que por e para um público restrito de empresas particulares, vinculadas ao mundo dos negócios. A necessidade gerada pela COVID-19, contudo, disseminou essa tecnologia, mudando hábitos e usos das pessoas.

Dessa feita, o necessário isolamento social revelou que a tecnologia de plataformas de webconferência estava pronta, mas não disseminada e que foi aperfeiçoada com incremento de novas funcionalidades, como por exemplo, capacidade de reprodução simultânea de muitas câmeras e capacidade de mais pessoas por reunião.

O segundo aspecto se vincula ao fato de que o ensino a distância foi beneficiado com a crise. De acordo com estudo desenvolvido pela Bain \& Company (2020), publicado pelo 
Estadão $^{4}$, no dia 04 de abril de 2020, haverá desigualdade na recuperação de vários setores após a crise do coronavírus. No entanto, o ensino a distância é um dos setores que mais se destacaram positivamente na crise, devendo se manter em alta a longo prazo. O resultado dessa pesquisa se reflete de forma similar, quando olhamos para o cenário de oferta dos cursos de graduação da UFGD, em que, como já apresentado, conseguiu retornar mais facilmente às aulas, superando mais rapidamente as dificuldades de percurso.

No entanto, os sinais de avanço do Educação a Distância, pode ser comprovado antes da pandemia, por meio do Censo da Educação Superior de 2019, disponibilizado pelo Instituto Nacional de Estudos e Pesquisas Educacionais - INEP. Com a divulgação dos resultados em outubro de 2020, temos acesso à informação de que, em 2019, o número de vagas ofertadas em cursos de graduação foi de 10.395.600, na modalidade a distância, enquanto que na modalidade presencial, o quantitativo foi de 6.029.702 vagas (BRASIL/INEP, 2019, p. 12).

Efetivamente, o número de ingressantes em cursos de graduação a distância, saltou de 16,1\%, em 2009, para 43,8\%, em 2019, enquanto nos últimos cinco anos constatou-se a diminuição de $14,3 \%$ de ingressantes nos cursos de graduação presenciais, como pode ser constatado na Figura 1, abaixo:

Figura 1 - Indicadores Educacionais

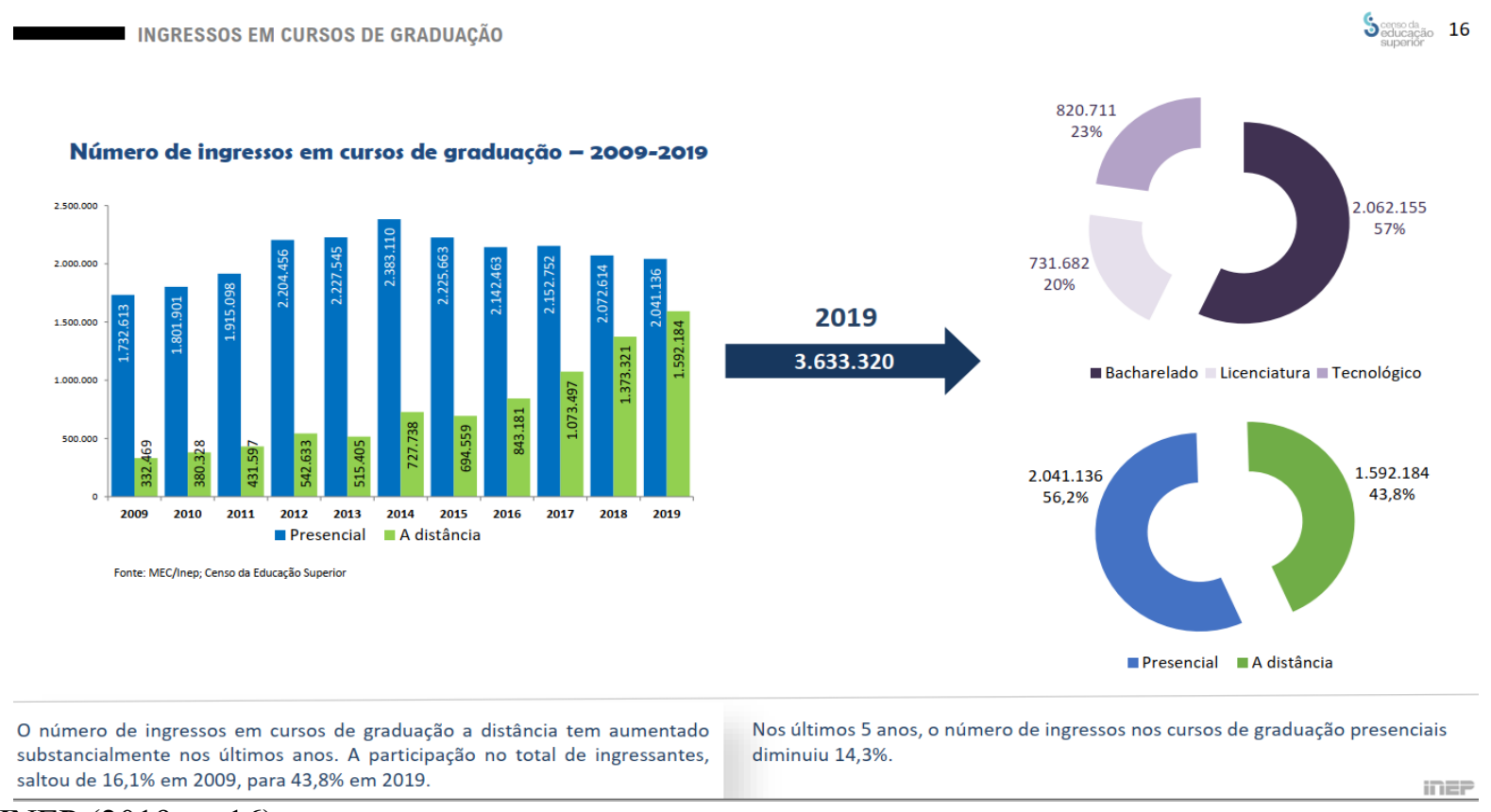

Fonte: INEP (2019, p. 16)

4 Disponível em: https://economia.estadao.com.br/noticias/geral,setores-economicos-terao-recuperacaodesigual,70003260430. Acesso em: 08 fev. 2021.

RIAEE - Revista Ibero-Americana de Estudos em Educação, Araraquara, v. 16, n. 2, p. 377-390, abr./jun. 2021. e-ISSN: 1982-5587 
Se em 2019, antes da crise gerada pelo coronavírus, a Educação Superior, no âmbito da graduação em cursos de ensino a distância, com o respaldo do Decreto $n^{0}$ 9057/2017 (BRASIL, 2020), é de se esperar que se confirme a projeção feita pelo estudo de Brain \& Company que indicam que a $\mathrm{EaD}$, manter-se-á aquecida quando a crise passar. Isso, porque é inegável que as metodologias e as tecnologias utilizadas na EaD subsidiaram escolas, que precisaram fechar seus espaços, presencialmente, na adoção de novos formatos de ensino. Nos últimos oito meses acompanhamos pelos noticiários, crianças e jovens tendo aulas em plataformas de ensino remoto, exigindo dos espaços escolares, sobretudo, dos professores, atualização na formação continuada para lidar adequadamente com o planejamento, a mediação e a avaliação de conteúdos para disponibilização em ambientes digitais.

O terceiro e último ponto desta abordagem remete à rapidez com que o marco regulatório relativo ao ensino para enfrentamento da pandemia, foi disponibilizado por parte do governo federal, Ministério da Educação (MEC) e Conselho Nacional de Educação (CNE), para dar legalidade, sustentação e validade das ações educacionais realizadas em ambientes virtuais, aspecto, inclusive, admitido neste texto, como impacto ao cenário educacional.

Os documentos cuidaram em conceituar ensino remoto, Educação a Distância e aprendizagem mediada por tecnologia. As aulas on-line, tanto da Educação Básica, como do ensino presencial e da própria $\mathrm{EaD}$, que se tem vivido nos últimos meses, no Brasil, mostram que os cenários educacionais diversos têm suas especificidades e realidades, quanto ao acesso e autonomia da tecnologia, mas que, apesar das dificuldades de muitos espaços, reconhece-se que o ensino por computador e/ou celular ligado à internet tem ajudado a comunidade educacional a refletir e considerar incorporar no ensino presencial outros formatos de aula e de aprendizagem.

Como dito na introdução deste artigo, refletir sobre a trilha pedagógica a fim de atingir as finalidades presentes na LDB no 9.394/96 (BRASIL, 1996) e incorporar nas aulas, em todos os níveis, as melhores práticas, além de fazer parte do movimento inerente à técnica e à tecnologia educacional, vai ao encontro do perfil do estudante, caracterizado como a geração $\mathrm{Z}$, e que compõem um coletivo social caracterizado por permanente mudança (BEZERRA et al., 2019). A educação, composta por professores, gestores, estudantes, modalidades educacionais, escolas, marco regulatório, áreas do saber, não tem um fim em si mesma, mas ganha força e valor na medida, "na aquisição de novos discursos", como defende Martins (2020, p. 2172), em que serve de instrumento para ajudar as pessoas na autonomia intelectual, no exercício da ética, da paz, da cidadania, na inserção ao mercado de trabalho e no equilíbrio emocional. 


\section{Prognósticos acerca dos cursos de graduação pós coronavírus}

Quando constatamos que, tanto ensino presencial como ensino a distância estão sendo realizados em formato metodológico similar, utilizando as mesmas tecnologias, de forma imposta, dada à situação vivenciada, nos ajuda a prospectar que a educação se fortalece na medida em que ambas modalidades se aproximaram ao ponto de encontrarem entre elas mais pontos de intercessão, afinal não é uma questão de ensino presencial versus ensino a distância, mas de que os saberes no formato de uma modalidade educacional pode reverter beneficamente em prol da outra.

Com isso queremos dizer que o ensino híbrido é uma consequência? Talvez, não. Uma saída interessante, para o fortalecimento da educação no Brasil é o desenvolvimento de um modelo educacional que garanta autonomia financeira para que as IES, no âmbito federal, estadual e municipal, possam realizar a Educação a Distância como amplificação do ensino presencial, respeitando o curso presencial, na sua lógica de desenvolvimento, podendo capturar a aula, por meio de webconferência, em tempo real, mas eternizando-a na conversão da live em videoaula.

Se, por um lado, os estudantes que fazem o curso remotamente, vão ter acesso ao mesmo conteúdo do estudante do presencial, por outro lado, os estudantes da aula presencial vão dispor do registro das aulas em AVA. Podendo, ainda, contratar professores para atuar em colaboração com o professor titular da disciplina, não para funcionar como tutores, mas para fortalecer a mediação pedagógica no ambiente virtual e viajar para encontrar os estudantes nas cidades polo, quando for o caso, conforme previsto no projeto pedagógico do curso. A contratação de professores não anula o concurso público que deve ser estimulado para que se mantenha ativa e forte, institucionalmente, a equipe docente dos cursos. Há necessidade de contratação de técnicos e equipe multidisciplinar, mantendo-se ativa, igualmente, a equipe básica de servidores técnicos, estimulando-se o concurso público para preenchimento do quadro de vagas.

O vestibular de um curso ofertado nessas condições deverá prever o total de vagas no curso presencial e nos polos advindos da articulação com as cidades que se interessarem com a formação a ser ministrada. As vagas, portanto, deverão ser mérito do presencial e da $\mathrm{EaD}$, onde ambas modalidades se unem e fortalecem, não a si mesmas, apenas, mas à universidade, diversos municípios e, por consequência, o Brasil. Isso requer criação de lei específica para incorporar as especificidades didático-pedagógicas e gerenciais da EaD. Tais pensamentos 
não deixam de se encaixar no ciclo da técnica e da tecnologia que muda e se transforma sempre que a sociedade apresenta necessidades de mudança no seu estilo de vida.

\section{Considerações finais}

Ao elencar os impactos e desafios do ensino on-line decorrentes da pandemia COVID19, deixamos estabelecido que a abordagem empreendida no texto versaria sobre as modalidades de educação presencial e a distância. Mostramos que o marco regulatório construído no cenário pandêmico foi direcionado à Educação Básica e Superior. Para dar mais clareza ao leitor, apresentamos, mais especificamente, o contexto da UFGD, a fim de mostrar localmente, os caminhos seguidos no ensino de ambas modalidades.

Os impactos identificados foram vinculados à interrupção da agenda pedagógica, bem como à migração do ensino presencial para o formato de ensino remoto. Com isso, restaram como desafio, a continuidade das aulas readequando o modelo pedagógico ao tempo em que professores e estudantes, sobretudo, do ensino presencial, aprenderam a lidar com a realidade de ensino e de aprendizagem de aulas virtuais, síncronas e assíncronas.

Mesmo com o avanço da tecnologia digital, constata-se que o ensino presencial e a $\mathrm{EaD}$ caminham em vias distintas, em suas ofertas de cursos, tanto no setor público como no privado. Isso denota via média no alcance dos objetivos. Se a universidade tem a missão institucional de ofertar educação de qualidade, há que se refletir como proporcionar meios de que o ensino seja viabilizado a regiões mais distantes, geograficamente, das cidades universitárias. O ideal é evitar o caminho dicotômico do ensino presencial versus ensino a distância, ou nosso ensino no "cuspe e giz" e o deles na via web, o que leva, quase sempre ao errôneo juízo de valor comparativo entre as duas modalidades. Para compensar o distanciamento, tem-se visto ampla oferta de lives de professores no YouTube, de ampla natureza e abordagem, mostrando que muitos professores não só superaram o bloqueio tecnológico, como incorporaram o uso de diversas tecnologias na educação.

Contudo, a adaptação do formato pedagógico das atividades letivas presenciais, como leitura e discussão de textos, uso do quadro de escrever, uso do caderno para as anotações, perguntas e respostas dialogadas olho no olho e realização de atividades avaliativas para o ambiente virtual se mostra desafiante para professores e estudantes, tanto pela tecnologia, devido ao conjunto de saberes que se fez necessário aprender, como pela imposição. Apesar de esses dois segmentos, presencial e $\mathrm{EaD}$, utilizarem em seu cotidiano recursos digitais, como internet, celular, notebook, computador ou tablet, o certo é que a ruptura do encontro 
presencial não tem sido aceita com facilidade. No entanto, enquanto perdurar o estado pandêmico decorrente da COVID-19, e houver necessidade de isolamento social como estratégia para evitar contaminação, sabe-se que as ferramentas para ensino on-line, aliadas à vivência de professores e estudantes nos mais diversos espaços virtuais, desde março de 2020, conseguem manter ativo o fluxo educacional, até que se tenha solução satisfatória para trazer de volta a rotina de professores e estudantes nas salas de aula, prospectando-se, contudo, a incorporação dos saberes virtuais nas aulas presenciais.

\section{REFERÊNCIAS}

BEZERRA, M. M. et al. Geração Z: relações de uma geração hipertecnológica e o mundo do trabalho. Revista Gest. Anál. Fortaleza, v. 8, n. 1, p. 136-149, jan./abr. 2019. e-ISSN 2359618X. DOI: http://dx.doi.org/10.12662/2359-618xregea.v8i1.p136-149.2019

BRAIN \& COMPANY. Setores econômicos terão recuperação desigual após crise do coronavírus. Estadão, 04 abr. 2020. Disponível em:

https://economia.estadao.com.br/noticias/geral,setores-economicos-terao-recuperacaodesigual,70003260430. Acesso em: 29 nov. 2020.

BRASIL. Censo da Educação Superior 2019. Disponível em:

http://portal.inep.gov.br/web/guest/indicadores-educacionais. Acesso em: 29 nov. 2020.

BRASIL. Constituição (1988). Constituição da República Federativa do Brasil. Brasília, DF: Senado, 1988.

BRASIL. Decreto n. 9.057, de 25 de maio de 2017. Regulamenta o art. 80 da Lei n. 9.394, de 20 de dezembro de 1996, que estabelece as diretrizes e bases da educação nacional. Brasília, DF, 26 maio 2017. Disponível em: https://www.in.gov.br/materia//asset publisher/Kujrw0TZC2Mb/content/id/20238603/do1-2017-05-26-decreto-n-9-057-de25-de-maio-de-2017-20238503. Acesso em: 15 nov. 2020.

BRASIL. Instrução Normativa n. 19, de 12 de março de 2020. Estabelece orientações aos órgãos e entidades do Sistema de Pessoal Civil da Administração Pública Federal - SIPEC, quanto às medidas de proteção para enfrentamento da emergência de saúde pública de importância internacional decorrente do coronavírus (COVID-19). Brasília, DF, 13 mar. 2020. Disponível em: https:/www.in.gov.br/en/web/dou/-/instrucao-normativa-n-19-de-12-demarco-de-2020-247802008. Acesso em: 22 nov. 2020.

BRASIL. Lei n. 10.040 de 18 de agosto de 2020. Estabelece normas educacionais excepcionais a serem adotadas durante o estado de calamidade pública reconhecido pelo Decreto Legislativo $n^{\circ} 6$, de 20 de março de 2020; e altera a Lei ${ }^{\circ} 11.947$, de 16 de junho de 2009. Brasília, DF, 19 ago. 2020. Disponível em: http://www.planalto.gov.br/ccivil_03/_ato2019-2022/2020/lei/L14040.htm. Acesso em: 24 nov. 2020. 
BRASIL. Lei n. 13.979, de 06 de fevereiro de 2020. Dispõe sobre as medidas para enfrentamento da emergência de saúde pública de importância internacional decorrente do coronavírus responsável pelo surto de 2019. Brasília, DF, 7 fev. 2020. Disponível em: https://www.in.gov.br/en/web/dou/-/lei-n-13.979-de-6-de-fevereiro-de-2020-242078735. Acesso em: 22 nov. 2020.

BRASIL. Lei n. 9.394, de 20 de dezembro de 1996. Lei de Diretrizes e Bases da Educação Nacional. Diário Oficial da União: Seção 1, Brasília, DF, n. 248, p. 27833, 23 dez. 1996.

BRASIL. Medida Provisória n. 934, de 01 de abril de 2020. Estabelece normas excepcionais sobre o ano letivo da educação básica e do ensino superior decorrentes das medidas para enfrentamento da situação de emergência de saúde pública de que trata a Lei $n^{\circ}$ 13.979, de 6 de fevereiro de 2020. Brasília, DF, 01 abr. 2020. Disponível em: https:/www.in.gov.br/en/web/dou/-/medida-provisoria-n-934-de-1-de-abril-de-2020250710591. Acesso em: 22 nov. 2020.

BRASIL. Portaria MEC n. 343, de 17 de março de 2020. Dispõe sobre a substituição das aulas presenciais por aulas em meios digitais enquanto durar a situação de pandemia do Novo Coronavírus - COVID-19. Brasília, DF, 18 mar. 2020. Disponível em: https://www.in.gov.br/en/web/dou/-/portaria-n-343-de-17-de-marco-de-2020-248564376. Acesso em: 22 nov. 2020.

KUSSLER, L. M. Técnica, tecnologia e tecnociência: da filosofia antiga à filosofia contemporânea. Kínesis - Revista de Estudos dos Pós-Graduandos em Filosofia, Marília, v. VII, n. 15, p. 187-202, dez. 2015. e-ISSN: 1984-8900. DOI: https://doi.org/10.36311/19848900.2015.v7n15.5712

MARTINS, E. C. A educação social nos novos espaços e tempos: as realidades entroncadas da intervenção social e educativa. Revista Ibero-Americana de Estudos em Educação, Araraquara, v. 15, n. esp. 3, p. 2167-2187, nov. 2020. e-ISSN: 1982-5587. DOI: https://doi.org/10.21723/riaee.v15iesp3.14423

\section{UNIVERSIDADE FEDERAL DA GRANDE DOURADOS. Instrução Normativa}

PROGESP n. 04, de 17 de abril de 2020. Estabelece orientações às Unidades Acadêmicas e Administrativas da UFGD quanto à medida de teletrabalho, temporário, para prevenção do contágio e enfrentamento da emergência de saúde. Disponível em:

https://portal.ufgd.edu.br/secao/coronavirus/portarias-instrucoes-normativas. Acesso em: 22 nov. 2020.

UNIVERSIDADE FEDERAL DA GRANDE DOURADOS. Reitoria. Portaria RTR n. 194, de 13 de março de 2020. Dispõe sobre suspensão de viagens, recomendações e deliberações do COE. Disponível em: https://portal.ufgd.edu.br/secao/coronavirus/portarias-instrucoesnormativas. Acesso em: 22 nov. 2020.

UNIVERSIDADE FEDERAL DA GRANDE DOURADOS. Reitoria. Portaria RTR n. 205, de 18 de março de 2020. Dispõe sobre a suspensão do calendário acadêmico por 30 dias. Disponível em: https://portal.ufgd.edu.br/secao/coronavirus/portarias-instrucoes-normativas. Acesso em: 22 nov. 2020. 
UNIVERSIDADE FEDERAL DA GRANDE DOURADOS. Reitoria. Portaria RTR n. 249, de 13 de abril de 2020. Dispõe sobre a prorrogação "Sine Die" da suspensão do calendário acadêmico. Boletim Oficial de Atos Administrativos no 4060. Disponível em:

https://portal.ufgd.edu.br/secao/coronavirus/portarias-instrucoes-normativas. Acesso em: 22 nov. 2020.

WENCZENOVICZ, T. J. Ensino a distância, dificuldades presenciais: perspectivas em tempos de COVID-19. Revista Ibero-Americana de Estudos em Educação, Araraquara, v. 15, n. 4, p. 1750-1768, out./dez. 2020. e-ISSN: 1982-5587. DOI:

https://doi.org/10.21723/riaee.v15i4.13761

\section{Como referenciar este artigo}

ROCHA, E. M. LIMA, J. M. S. Impactos e desafios do ensino on-line decorrentes da pandemia COVID-19. Revista Ibero-Americana de Estudos em Educação, Araraquara, v. 16, n. 2, p. 377-390, abr./jun. 2021. e-ISSN: 1982-5587. DOI: https://doi.org/10.21723/riaee.v16i2.14526

Submetido em: 30/11/2020

Revisões requeridas em: $21 / 12 / 2020$

Aprovado em: 26/01/2021

Publicado em: 01/02/2021 